\title{
Seismic reliability and cost evaluation for a hospital lifeline network system
}

\author{
K. Fuchida \\ Department of Civil \& Architectural Engineering, \\ Yatsushiro College of Technology, Kunamoto, Japan
}

\begin{abstract}
This paper presents an evaluating method for seismic reliability and costs of a lifesaving lifeline connecting to a hospital during an earthquake. By using the reliability analysis method for a lifeline network based on the Monte Carlo method, reliability of a virtual model and a real one of Yatsushiro-city water supply pipeline network is evaluated. Numerical computations are performed for models with various conditions of ground and pipes. As a result, in a case of seismic intensity 5 , the reliability of a pipeline connecting to a hospital near the sea side is low. In a case of seismic intensity 6 , all nodes connecting to hospitals have very low reliability and this suggests that other methods of preparing for earthquakes are needed except improving method of conditions of grounds or pipes.
\end{abstract}

Keywords: lifeline, reliability, network, cost.

\section{Introduction}

Severe damages of lifeline systems during earthquake much affect the social activity and urban life of citizens. It is very important that aseismic investment for lifesaving lifeline systems is performed in view of fast recovery of economical and social works in urban area after earthquakes.

This study aims to investigate the seismic reliability and costs of a lifesaving lifeline connecting to a hospital during earthquake. The cost is evaluated by the sum of aseismic investment (mainly pipeline reinforcement and ground improvement), restoration cost and system-down cost with the system reliability, and then discuss the effective investment by minimizing the total cost of every pre-investment and post-repairing cost. For the assumption model of water 
supply pipeline network and real one in Yatsushiro city, the relations between reliabilities and conditions of pipeline and ground are investigated.

\section{Analytical method}

The flow of the reliability analysis in this study is shown in Figure 1(Akiyoshi [1]). In the first step, the network of water supply pipelines is modeled into the node-link discrete system and the failure probability of each link is evaluated by the Quantification theory I. The seismic intensity distribution for future earthquakes in the objective area is induced by using the past occurrence records of earthquakes in the respective area. The probability of the occurrence of earthquakes within a period is evaluated.

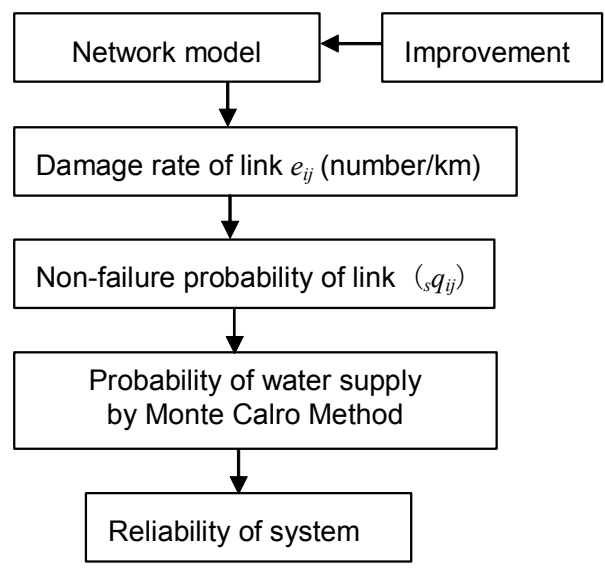

Figure 1: $\quad$ Flow of reliability analysis.

The failure of pipeline is dependent on the seismic intensity, the ground characteristics and the pipeline characteristics. By unifying the failure data of past earthquakes, which are Miyagi-ken-oki (1978), Nihonkai-chubu (1983), Kushiro-oki (1993) and Hyogo-ken-nanbu (1995), with the Quantification theory $\mathrm{I}$, the equation of regression for the failure ratio of water supply pipeline is derived (Kubo [2] and Hino [3]) in terms of the category weights which are shown in Table 1. In this process the occurrence of liquefaction is estimated by the method of JRA [4].

In the second step of this analysis, the reliability for each link of a water supply system is computed by Monte Carlo simulation technique (Tamura [5]) as the corresponding failure probability which is based on the Quantification theory I, in terms of earthquake intensity, stiffness of ground, scale of liquefaction and type of pipes. In this process, the connectivity of the system is defined as the rate of existing path among the pair of nodes, and the probability of system connectivity is also evaluated by the Monte Carlo simulation. 
Table 1: $\quad$ Results of quantification theory analysis.

\begin{tabular}{|c|c|c|}
\hline Item & Category & Category weight \\
\hline \multirow{3}{*}{$\begin{array}{l}\text { Seismic } \\
\text { intensity }\end{array}$} & $\mathrm{V}(80 \sim 250 \mathrm{gal})$ & 0.301 \\
\hline & VI $(250 \sim 400 \mathrm{gal})$ & 2.331 \\
\hline & VII ( >400gal) & 23.292 \\
\hline \multirow{3}{*}{ Ground type } & 1 & 1.000 \\
\hline & 2 & 12.610 \\
\hline & 3 & 12.800 \\
\hline \multirow{3}{*}{ Liquefaction } & Remarkable & 1.000 \\
\hline & Slightly & 0.732 \\
\hline & None & 0.137 \\
\hline \multirow{5}{*}{ pipeline type } & Cast iron & 0.517 \\
\hline & Ductile cast iron & 0.065 \\
\hline & Steel & 0.045 \\
\hline & Asbestos cement & 0.676 \\
\hline & PVP & 0.046 \\
\hline \multirow{4}{*}{$\begin{array}{c}\text { Diameter of } \\
\text { pipeline }\end{array}$} & $50 \sim 125 \mathrm{~mm}$ & 1.000 \\
\hline & $150 \sim 300 \mathrm{~mm}$ & 0.446 \\
\hline & $350 \sim 600 \mathrm{~mm}$ & 0.052 \\
\hline & $>700 \mathrm{~mm}$ & 0.012 \\
\hline
\end{tabular}

In the next step of this study, the effects of aseismic investment on the reliability of the lifeline system, the loss of damage and the restoration cost of the system are investigated as the flow shown in Figure 2. Aseisimc investment for the lifeline is assumed to include the initial cost for strengthening of pipes and liquefaction-preventing ground improvement. In this study the total cost (TC:in eq.(1)) is used as the index for optimal aseismic investment, where the total cost is expressed as the sum of the restoration cost (RES), the industrial loss due to system-down (SDC) and the reinforcement cost (RC) as

$$
E(T C)=E(R E S)+E(S D C)+R C
$$

where

$$
\begin{gathered}
E(R E S)=\sum_{i=1}^{n} D N_{i} \times R E S_{i} \\
E(S D C)=C P \times P R O B_{i}(S W) \times D A Y_{i} \\
R C=\sum_{i=1}^{n} R P_{i}+\sum_{i=1}^{n} R G_{i}
\end{gathered}
$$

and $E\left(\right.$ ) means expected value, $D N_{i}$ : number of failures of i-th damaged link, $R E S_{\mathrm{i}}$ : restoration cost of $\mathrm{i}$-th reinforced link, $C P$ : total cost of industrial 
production per day in Yatsushiro city, $P R O B_{i}(S W)$ : probability of suspension of water of $\mathrm{i}$-th reinforced link, $D A Y_{\mathrm{i}}$ : dates for restoration of $\mathrm{i}$-th reinforced link, $R P_{\mathrm{i}}$ and $R G_{\mathrm{i}}$ : reinforcement cost of pipeline and ground, respectively. The unit prices and computations used here are followings (Takada [6]):

(1) improvement of ground (SCP): 3000(yen) /m (depth) / (number of pile)

(2) improvement of pipeline: 100000 (yen) /m (length)

(3) restoration cost: 10million (yen) / number of restoration

(4) industrial production: 1.4 billion (yen) / day

(5) water charge: 40 (yen) / person / day

(6) water supply population: 36800 people

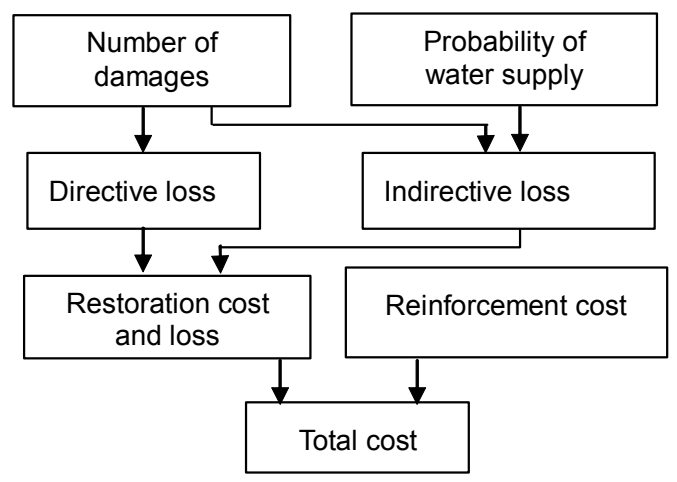

Figure 2: $\quad$ Flow of cost evaluation.

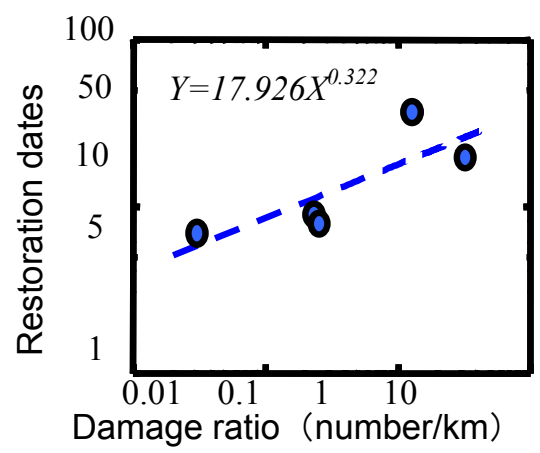

Figure 3: $\quad$ Relation between restoration rate and damage ratio.

The dates of restoration are related by the regression analysis with damage ratio as shown in Figure 3 (Hino [3]). The order of priority for aseismic reinforcement is determined by the algorithm of the shortest-path assignment based on the Dijkstra's method (Civil Planning Research Committee [7]). Two patterns of the restoration strategy are assumed for performing the aseismic reinforcement, in which one is in order of least costed links and the other is in order of much damaged links. 


\section{Results and considerations}

Numerical computations for the aseismic investment and the reliability for the lifeline systems are conducted for the water supply pipeline system models in assumption case and Yatsushiro city.

Figure 4 shows the assumption model of water supply pipeline system for evaluation the relations between the seismic reliability and aseismic conditions. This area is divided to the mesh of $0.5 \mathrm{~km} \times 0.5 \mathrm{~km}$ and the conditions of pipes and the ground in one mesh are assumed to be same. Two types of the aseismic reinforcement are assumed, in which one is the reinforcement of pipeline segment and the other is the reinforcement of the ground by improvement method against liquefaction.

Figure 5 and Figure 6 show the relations between reliability and improvement numbers of pipe and ground, for respectively. In both Figures 5 and 6 , the initial conditions of the grounds and pipes are seismic intensity 6 , ground classification type 2 , slightly liquefaction, cast iron pipe and diameter of pipe $150 \mathrm{~mm}$. In the case of improvement of pipe type from cast iron pipe to steel one in Figure 5, reliability increases from 0.2 to 0.5 . In the case of improvement of the ground from type 2 to type 3 in Figure 6, the reliability of the system increases from 0.2 to 0.9 . The result of Fig. 6 means that the ground improvement is effective for increasing the reliability of the system.

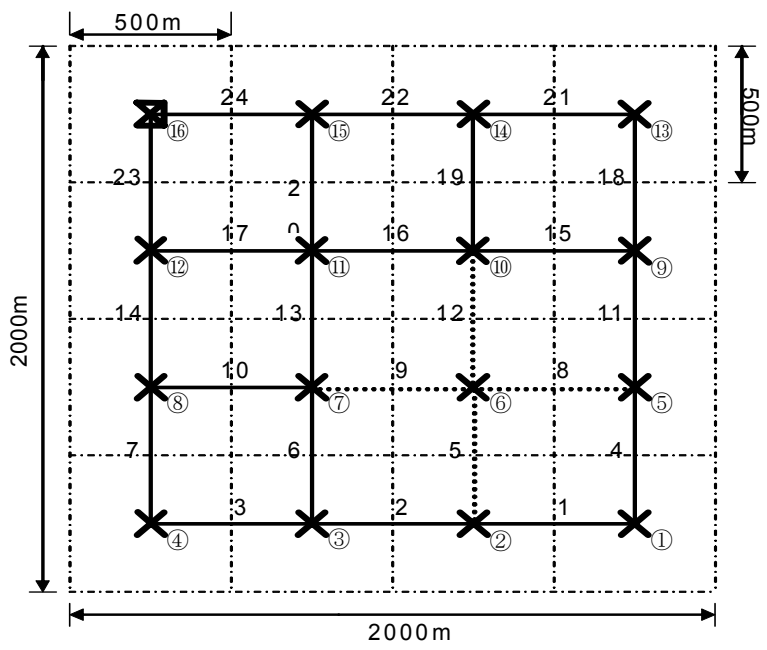

Figure 4: $\quad$ Assumption model of network.

Figure 7 shows the relation between the cost and reliability (the water supply rate) as the corresponding failure probability within 100 years. In Figure 7 it needs the total cost about 1.6 billion Yen for the water supply rate of about $50 \%$, which means that the aseismic investment is not effective. 


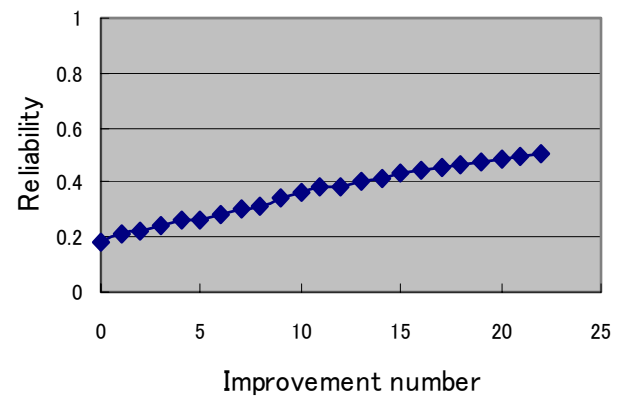

Figure 5: Reliability versus improvement number of pipe.

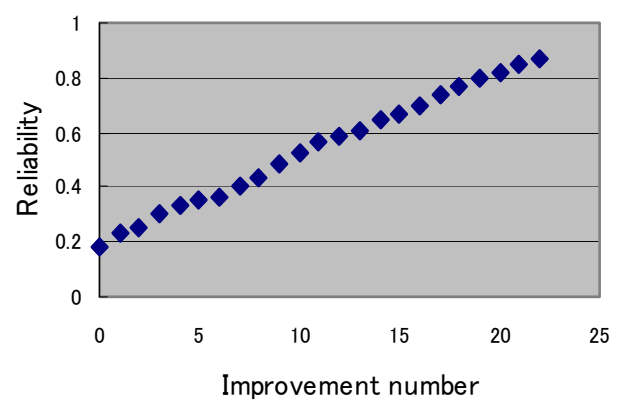

Figure 6: Reliability versus improvement number of ground.

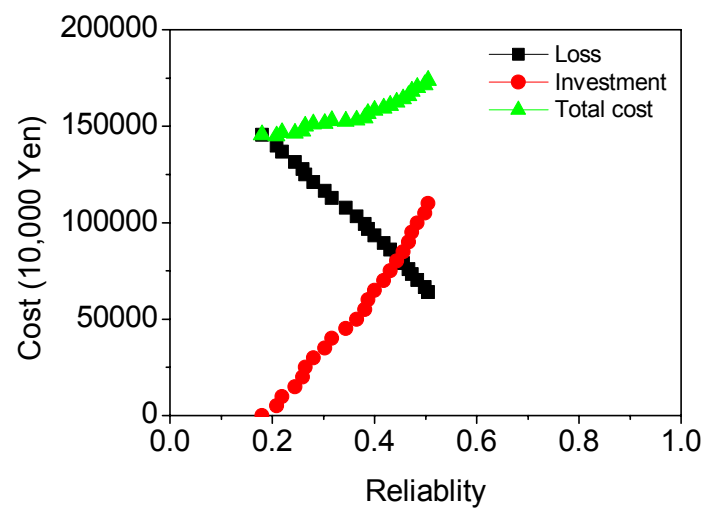

Figure 7: Relation between cost and reliability. 


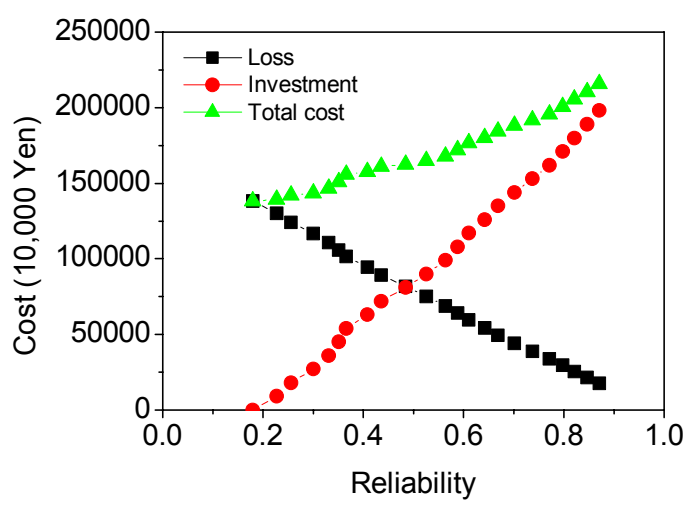

Figure 8: Relation between cost and reliability.

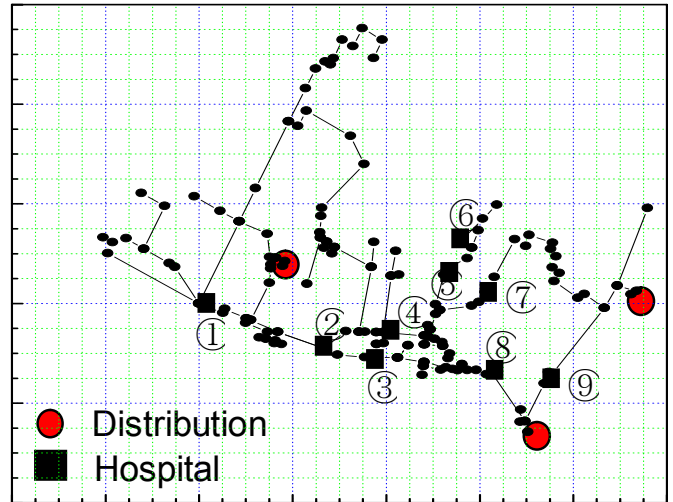

Figure 9: Water supply model of Yatsushiro city.

Figure 8 shows the relations between the total cost and reliability (water supply rate) for the case of improvement of ground type as same as in the case of Figure 6 . The total cost increases with reliability and maximum cost reaches about 2.1 billion Yen for the reliability about 0.9 , which means that a little investment is effective for increasing the water supply rate.

Figure 9 shows the water supply pipeline model in Yatsushiro city in which this area expanded in $12 \mathrm{~km}$ (EW direction) $x 8 \mathrm{~km}$ (NS direction), and the pipeline system is modeled for the distribution lines of the diameter larger than $50 \mathrm{~mm}$ as 146 links, 138 nodes and 3 distribution basins. This area is divided to the mesh of $500 \mathrm{~m} \times 500 \mathrm{~m}$. The conditions of the ground in one mesh are assumed to be same. 
Table 2 shows the reliabilities of nodes which are connected to the nine hospitals in Yatsushiro city for the cases of seismic intensity 5 and 6. In Table 2, the reliability means the water supply rate from the basin to the node. The average value of the reliability in whole Yatsushiro city is about 0.787 and 0.203 for the seismic intensity 5 and 6 , respectively.

In the case of seismic intensity 5 the reliability 0.642 of the hospital A (No.1) is lower than the averaged value of Yatsushiro city, which means that the hospital A locates near the shore line and the ground is possible to be liquefied. The reliabilities of the hospital $\mathrm{G}$ and $\mathrm{H}$ which locate near the mountain are high. In the case of seismic intensity 6 the reliabilities of the almost hospitals are very low values. This suggests that another countermeasure is needed except physical ones like reinforcement of pipeline and ground improvement.

Table 2: $\quad$ Reliability of hospital lifeline.

\begin{tabular}{|c|c|c|c|c|}
\hline \multirow{2}{*}{ Hospital } & \multirow{2}{*}{ Link } & \multirow{2}{*}{ Node } & \multicolumn{2}{|c|}{ Reliability } \\
\cline { 4 - 5 } & & & Intensity 5 & Intensity 6 \\
\hline (1) $\mathrm{A}$ & 49 & 16 & 0.642 & 0.021 \\
\hline (2) $\mathrm{B}$ & 63 & 60 & 0.860 & 0.058 \\
\hline (3) $\mathrm{C}$ & 72 & 67 & 0.935 & 0.058 \\
\hline (4) $\mathrm{D}$ & 77 & 70 & 0.931 & 0.160 \\
\hline (5) $\mathrm{E}$ & 87 & 82 & 0.879 & 0.101 \\
\hline (6) $\mathrm{F}$ & 91 & 85 & 0.790 & 0.048 \\
\hline (7) $\mathrm{G}$ & 97 & 93 & 0.918 & 0.132 \\
\hline (8) $\mathrm{H}$ & 124 & 117 & 0.937 & 0.239 \\
\hline (9) $\mathrm{I}$ & 136 & 126 & 0 & 0 \\
\hline
\end{tabular}

\section{Conclusions}

In this study, the relations between the system reliability, conditions of ground and pipe, and the aseismic investment are investigated for the assumption model of the water supply pipelines, then the water supply pipelines in Yatsushiro city are modelled as network and the reliabilities of hospital lifeline in Yatsushiro city are investigated. Conclusions are summarized as follows:

1) Reliabilities of network depend on the pipe types and ground conditions and have low values for cast iron or asbestos cement pipe, middle or small diameter pipe, and ground possible to be liquefied.

2) It is difficult to increase the reliability of the network system by the preearthquake investment for improving pipeline. It is possible to increase the reliability of the system and decrease the total cost of it by the pre-earthquake investment for improving ground.

3) For the hospital lifeline network in Yatsushiro city, the reliability of the hospital locating near shore line is low in the case of seismic intensity 5 and the 
reliability of all hospital decrease in the case of seismic intensity 6 . Thus another countermeasure except physical ones is needed in seismic intensity more than 6 .

\section{References}

[1] Akiyoshi, T., Fuchida, K. \& Maeda, S., An Estimation Method on Aseismic Investment for Lifeline Systems, Proc. of 10th Earthquake Engineering Symposium, Vol.3, pp.3187-3192, 1998 (in Japanese).

[2] Kubo, S., Estimation of Seismic Damage and Restoration of Lifeline System, Master Thesis for Kumamoto Univ., 1984 (in Japanese).

[3] Hino, A., Optimization of rational aseismic investment for lifeline, Master Thesis for Kumamoto Univ., 2000 (in Japanese).

[4] Japan Road Association, Specifications for highway bridges, Part $V$ Earthquake -resistant design, JRA, 1996 (in Japanese).

[5] Tamura, C. and Kawakami, H., Seismic risk analysis of underground lifeline system by use of Monte Carlo method, Proc. of JSCE, No.311, pp.37 48, 1981 (in Japanese).

[6] Takada, S., Direct and indirect economic losses of Kobe water systems during the1955 Hyogoken-Nanbu Earthquake, Proc. of Third ChinaJapan-US Trilateral Symposium on Lifeline Earthquake Engineering, pp.291-300, 1998.

[7] Civil Planning Research Committee, Analysis and planning of traffic network - newest theory and application - Text of Civil Planning Course, JSCE, pp.33 38, 1987 (in Japanese). 